\title{
The Effect of High-Speed Rail on Regional Economy in China Using AHP
}

\author{
Xiangju Ren*, Qi Ding \\ School of Economics and Management, Chang An University, Xi'an City, China \\ Email address: \\ 904819567@qq.com (Xiangju Ren), 1213814714@qq.com (Qi Ding) \\ ${ }^{*}$ Corresponding author
}

\section{To cite this article:}

Xiangju Ren, Qi Ding. The Effect of High-Speed Rail on Regional Economy in China Using AHP. International Journal of Transportation Engineering and Technology. Vol. 5, No. 4, 2019, pp. 111-117. doi: 10.11648/j.ijtet.20190504.18

Received: November 3, 2019; Accepted: December 25, 2019; Published: December 26, 2019

\begin{abstract}
The opening of the high-speed rail is a technological revolution in the transportation industry, which reflects the comprehensive strength of the country to some extent. It generated a lot of researches on high-speed rail in transportation, tourism, economy, etc. However, there are few studies on the impact of high-speed rail on regional economic development by the analytic hierarchy process. On the basis of reading and collating related literature, the paper put forward the quantitative and qualitative methods in effect of high-speed rail (HSR) on regional economic development. According to the theory of Regional Economy development and the practical condition of high-speed rail in China, this paper provides a new evaluation index system including 2 layers (direct and indirect effects), and establishing 6 indexes for the effect of high-speed rail on regional economy in China. The weights of factors in index system are gave by using Analytic Hierarchy Process. The main conclusion from the paper is that high-speed rail a direct impact on the regional economy is greater than indirect And the following of the ranking result of the indicator regional: passenger traffic $>$ node accessibility $>$ regional investment benefit $>$ tourism development $>$ regional industrial structure $>$ urbanization levels. This is not only a great significance to the development regional economy of China, but also applicable to other districts for the development of local economies by HSR.
\end{abstract}

Keywords: Regional Economy Effect, High-speed-rail, AHP

\section{Introduction}

This high-speed rail has great impact on domestic regional difference in economic development. And also is a revolution in traffic transport industry. In addition to the direct benefit on the construction and operation from high-speed rail, it is significant among the rapid flow of different production factors optimization of regional allocation of resources and the connection between the nodes in the region when high speed rail begin to construct. Therefore, this research is important that regional economic problems is effected by high-speed-rail. Regional economic life is improved by a mode of transportation. The thesis has theory signification and engineering application value. According to the characteristics of high-speed rail and relevant theoretical knowledge of regional economy, the influence is quantified.

Foreign research of high-speed railways is represented by the French TGV and the Japanese Shinkansen. Their results were as follows: urban accessibility, urban population and industrial structure were increased in various degree. In recent years, domestic scholars have studied many high-speed railway passenger lines, which have affected the economy, transportation and tourism, such as the Beijing-Kunming high-speed rail, Wuhan-Guangzhou high-speed rail, haerbin-dalian high-speed rail and so on.

With more people choosing high-speed train prime type of travel, the impact of HSR on China's regional economic development is expected to be computed quantitatively. However, several questions related to the effectiveness of HSR operation and investment remain to be explained. For instance, questions such as to what extent largely used HSR systems have changed regional accessibility and more fundamentally, what degree deployed HSR have changed in the proportion of the three major industries, what proportion HSR systems have influenced on regional tourism income and the number of people, and what affect regional economy for High-Speed Rail?

However, there are few studies on the impact of high-speed 
rail on regional economic development by the analytic hierarchy process. The aim for this study is to answer these questions by conducting assessment mainly from three perspectives. First, we explains the linkages between HSR and regional economic from other literatures. Second, the regional economics levels are measured using six different indexes: regional passenger traffic, regional investment benefits, node accessibility, industrial structure, urbanization levels, and tourism development. Third, the different indicators weights on regional economic growth and HSR are calculated quantitatively and qualitatively based on AHP. Therefore, this paper mainly clarifies the impact of high-speed rail on regional economic development.

In this paper, we will introduce the new methodology in explain the economics effect of HSR. AHP is an method to decision making that involves structuring multiple choice criteria into a hierarchy in the relative these criteria importance, alternatives for each criterion and an overall ranking of the alternatives for evaluating core competence of China's High-Speed Rail [1]. So AHP helps to capture both subjective and objective evaluation measures. Hierarchy Process method uses fuzzy mathematics changing qualitative analysis which indexes are difficult to be quntified into quantitative analysis in the model. Every index weight given by expert experience is used, which makes the evaluation more reasonable.

The rest of the paper is organized as follows. Section 2 provides a review of the literature on high speed rail in China, which serves as the theoretical foundations for our empirical assessment. Section 3 introduces regional economic and HSR development. Section 4 provides model construction principle by the AHP. Section 5 presents the regional economics on influence of using different indicators and calculating their weights by AHP. Section 6 and secion7 discusses and concludes.

\section{Literature Review}

There are many studies on the impact of many high-speed rails on the economy, transportation, and tourism, which are mainly embodied in terms of regional accessibility, regional growth, industrial structure, and urbanization. There are many studies on the impact of many high-speed rails on the economy, transportation, and tourism, which are mainly embodied in regional accessibility, regional growth, industrial structure, and urbanization.

\subsection{Study on Regional Accessibility}

This is correlation study on regional accessibility. This literature suggests the change of accessibility from the central city to the node city in the Beijing-Shanghai region, and discusses the impact of high-speed rail on the accessibility of the central city [2]. By explaining and comparing different accessibility index, it shows the impact of transportation infrastructure construction impels the integration of transportation and economy [3]. U. BlumK proposed that Contributed to the high-speed rail, different nodes accessibility is obvious, and the accessibility of node cities will increase [4]. Through three periods, the economic integrity of this node city is analyzed.

It is analyzes that the increased accessibility and network economy for coming of high-speed rail, which are helpful to EU countries and cities in Europe, but cities on the edge of high-speed rail nodes need further development by Coto-Millan [5]. Zhu Yi contribute to the literature based on real travel time by train between station pairs and analyzing HSR's potential impacts on the spatial disparity of China. Finding that the development of HSR has significantly increased the economic potential of Chinese cities [6]. $\mathrm{Xu}$ Wcalculates the connectivity and accessibility indices of China's high-speed railway network in different time periods, and find regional accessibility is increase [7].

\subsection{Structure of the Regional Industry and Passenger Capactity}

The second part concerns structure of the regional industry and Passenger Capactity. The paper analyzes the effect of Shanghai-Hangzhou high-speed rail on the industrial structure of Hangzhou, and mainly focuses on the analysis of tourism, commerce, real estate, manufacturing, and service industries, and puts forward the response strategy of Hangzhou [8]. Building a high-speed railway will not only promote the economic growth of the cities at the county level. Jintao Ren also find that positive and significant policy effect on the three main industries by using Two-way Fixed Effect mode [9].

As provided byHuiYan Yu, it discusses the impact of the high-speed railway on the economic development of Liaoning from the perspective of the combination of passenger and freight volume, industrial structure and regional industrial benefits [10]. Fernand Martin believed that high-speed rail is conducive to the rational allocation of the transport passenger and transport market. So the transport capacity in a certain region has great growth [11].

\subsection{Changes in Regional Urbanization}

The third part focuses on changes in regional urbanization. Regional transportation has an important growth on economic development. The effect of high-speed rail in improving economic growth lies in its overflow effect [12]. For instance as indicated byZhengZE Yang, due to the influence of high-speed rail on the time distance, the transportation time between the central city and the node city is greatly shortened, the connection of cities is strengthened, and the urbanization has better promoting effect for surrounding [13]. The high-speed rail in Beijing-Tianjin-Hebei area promoted the development of regional economy in different degree from the planning project and invested funds to the final opening [14]. Gerard Mathieu studied the role of French high-speed rail in the economic development of surrounding cities [15]. The official operation of the Lyon high-speed rail station has a significant role in promoting the development of the regional urbanization. 


\subsection{Regional Investment Benefit}

Zhenhua Chen measures the regional regional economic impacts of high-speed rail using a dynamic SCGE model. The study finds that HSR infrastructure development in China has generated a positive regional economic effect. The growth rate of the real GDP stimulated by the productivity increase in rail transport sector and the stimulus effect of rail infrastructure capital investment [16]. From Zhenhua Chen, the rail network density is a proxy to reflect regional economic disparity in rail investment, and three accessibility indicators (weighted average travel time, potential ac-cessibility and daily accessibility) are evaluated the effect of rail network density onregional economic growth [17]. Note that rapid development of high-speed in China, It has been proposed an endogenous economic growth mode to express the powerful impact on urban economic growth by Shujie Yao [18]. Zhang Li use the investment promoting theory and input-output table to Put forward direct benefit on GDP brought by high-speed rail construction [19].

\subsection{Promoting Tourism Development}

Xin Wang applies the improved gravitational model and iso-tourist lines in proving the tourism effects created by the infrastructure of China's HSR [20]. Cherylynn Becker investigate the effects of a plan for the development of a rapid transit rail system in the United States by consumers' perceptions and anticipated uses of the proposed rail system, finding that the most of consumers are in touristic activities [21]. It believes the association between high - speed rail (HSR) operation and tourist arrivals in China using both system generalized method and synthetic control methods byLi, Leona S. Z [22]. Ömer Faruk Görçün analyses that high speed trains can make consumers choose more satisfier transportation type to tour. And owing to high speed rail (HSR) International and domestic tourism demands may increase owing to high speed trains (HSR) [23].

Of course, there are some papers that concerns on regional increasing economics. Most researchers systematically study single aspects of high-speed rail development on the economy, but there is no qualitative and quantitative comprehensive analysis for every aspects on economics development by high-speed rail. Therefore, it is particularly important to analyze the impact indicators using AHP.

\section{Regional Economic Effect and HSR Development}

\subsection{HSR Development}

The high-speed rail has rapidly developed, which play an important role in improving people's travel conditions, promoting economic growth along the line, upgrading of related industrial structures, and pushing the coordinated development of regional and urban. And it results in huge spillover effects. When the "four verticals and four horizontals" ended, high-speed rail construction is still continuing to advance rapidly, marching toward "eight vertical and eight horizontal".

Since 2011, China's high-speed railway operating mileage has increased year by year. Chinese high-speed railway operating mileage was 0.66 million kilometers In 2011. The national railway operating mileage reached 127,000 in 2017, with the annual increase of $2.4 \%$. The high-speed railway operating mileage reached 25,000 kilometers, accounting for $66.3 \%$ of the world's total high-speed rail. At the end of 2018 , China's high-speed railway operating mileage has reached 29,000 kilometers, making up more than two-thirds of the world's total mileage. It has become the country with the longest high-speed rail, the highest transportation density and the most complicated network operation scene. In 2018, it is estimated that the number of railway passengers sent by the HST is 3.313 billion, an growth of $9.0 \%$ year-on-year. And high-speed trains send 2.01 billion passengers, accounting for $60.4 \%$, an increase by $16.6 \%$.

\subsection{Regional Economic Effect}

The influence of high-speed railways on regional economy can be studied in two aspects: the directly and the indirectly influence on regional economies [24].

It can Improve regional railway transportation capacity. High-speed rail is the basic guarantee for social and economic development as carrier and new type of transit style. Compared with other transportation modes, high-speed rail have large transport capacity, shorter ride times. And it is affected little by weather. A standard high-speed rail can accommodate 1,061 people. With the emergence of high-speed rail, regional transport capacity become stronger than before.

High-speed rail can improve regional accessibility. Railway transportation has many advantages. For example, railways have low fares, large capacity, and less affected by weather. With the development of social and economic levels, the existing requirements of travel speed are not met. herefore, high-speed rail came into being with the advantages of high speed and the traditional railway. The core competitiveness is highest in five types of transportation (road transportation, water transportation, air transportation, pipeline, traditional railway transportation).

The appearance of HSR can change the regional industrial structure. The variations in the proportion of the first, second and third industries can reflect the comprehensive national power. Developed countries generally have a relatively large proportion of the tertiary industry. But China generally has a large proportion of the secondary industry, and only a few cities have a large proportion of the tertiary industry. High-speed railways provide challenges and opportunities for the development of secondary and tertiary industries and high-tech industries to promote the continuous upgrading of other industries, such as tourism, service, and manufacturing. The high-speed railway promotes the change of economic structure. It directly breaks the original regional pattern and the obstacle 
of space area, greatly reduces the spatial and time distance between the cities of each node, and brings a lot of employment opportunity to the surrounding cities. It provides development conditions for the industrial structure changes of the nodes and the central cities, promotes the integration of the three industries and can integrate different advantageous resources within the region in the different degrees of the industry. The industrial layout has been adjusted since the high-speed rail has further expanded. the scope of economic radiation in the surrounding areas, which promote the industrial structure changes and economic growth of the central cities.

The number of regional travelers is increasing for HSR's appearance. The macro economy is supposed to pursue balance between supply and demand. It can stimulate supply with demand, otherwise, visa verse. The high-speed rail has brought an increase in travel demand. As an industrial chain, high-speed railway can provide better travel services to improve customer travel satisfaction. Travelers have increased opportunities to choose in travel mode. In a word, the high-speed rail have great development potential from planning, construction to daily operation. From its construction and operation management to all aspects of work, it directly generates a large number of travel opportunities and saves a lot of travel time. So it stimulates the consumption of travel and indirectly increases the rate of GDP.

HSR can improve regional urbanization. The theory of growth poles is that regional economic growth contributes to regions with better location conditions and some industry-driven effects. It should be cultivated into economic growth poles such as suburb and high-speed rail station. The new growth pole can gradually develop into nodes with important location conditions, which the central cities or cities along the high-speed rail can further promote regional economic development and expand other businesses. The opening of high-speed rail has increased the flow of personnel and the number of migrants between the cities of the nodes. The high-speed rail station promotes the urbanization process. Economic development inevitably leads to the rapid development of urbanization. The level of urbanization is usually measured by the ratio of the permanent population dividing by total population. The economic radiation effect is strengthened, and further irradiated to other surrounding areas, and was accelerated for the urbanization process.

\section{Methodology}

\subsection{Index System of the Construction}

We should conduct a systematic analysis before establishing a hierarchical structure model. First of all, we must group the main factors involved. Then each group considers as a separate level and organizes the target problems. Finally construct a reasonable hierarchical structure model.

\subsection{Construct a Judgment Matrix Based on Expert Scoring Results}

It shows the importance of the two influencing factors by a comparison. Then construct a judgment matrix.

Table 1. Judgement matrix.

\begin{tabular}{lllll}
\hline Ak & B1 & B2 & $\ldots$ & Bn \\
\hline B1 & b11 & b12 & $\ldots$ & b1n \\
B2 & b21 & b22 & $\ldots$ & b2n \\
$\ldots$ & $\ldots$ & $\ldots$ & $\ldots$ & $\ldots$ \\
Bn & b11 & bn2 & $\ldots$ & bnn \\
\hline
\end{tabular}

For $\mathrm{Ak}, \mathrm{Bij}$ is a numerical representation of the relative importance of $\mathrm{Bi}$ to $\mathrm{Bj}$.

Table 2. The importance scale judgment matrix.

\begin{tabular}{ll}
\hline Importance scale & Meanings \\
\hline 1 & Unimportant \\
3 & Not so important \\
5 & Generally important \\
7 & Important \\
9 & Very important \\
$2,4,6,8$ & Intermediate value \\
\hline
\end{tabular}

The judgment matrix has satisfactory consistency, otherwise the judgment matrix needs to be adjusted.

\subsection{Single-level Sequencing}

The eigenvector corresponding to the largest eigenvalue of the decision matrix is normalized (so that the sum of the elements in the vector equals 1 ), and is denoted by W. The element of $\mathrm{W}$ is the ranking weight of the same level factor for the relative importance of a factor of the previous level factor. This process is called hierarchical single ordering.

\subsection{Consistency Test}

$$
\begin{gathered}
C I=\frac{\chi_{\max }-n}{n-1} \\
C R=\frac{C I}{R I}
\end{gathered}
$$

$\chi_{\max }$ is maximum eigenvalue,

$\mathrm{N}$ is $\mathrm{n}$ order matrix,

$\mathrm{RI}$ is mean random consistency index

When CR is less than 0.01 , the judgment matrix has satisfactory consistency, otherwise the judgment matrix needs to be adjusted. The larger $\chi_{\max }-n$ is, the bigger the $\mathrm{CI}$, and consistency of the judgment matrix is worse.

Table 3. Mean random consistency index of the matrix (RI).

\begin{tabular}{llllllllll}
\hline & $\mathbf{1}$ & $\mathbf{2}$ & $\mathbf{3}$ & $\mathbf{4}$ & $\mathbf{5}$ & $\mathbf{6}$ & $\mathbf{7}$ & $\mathbf{8}$ & $\mathbf{9}$ \\
\hline $\mathrm{RI}$ & 0.00 & 0.00 & 0.58 & 0.90 & 1.12 & 1.24 & 1.32 & 1.41 & 1.45 \\
\hline
\end{tabular}

\subsection{Hierarchy General Ranking}

Hierarchy general ranking needs to be performed from top to bottom. The order of the $\mathrm{n}$ elements on the $\mathrm{k}-1$ layer relative to the total target can be calculated. 


$$
w^{(k-1)}=\left(w_{1}^{(k-1)}, \cdots, w_{n}^{(k-1)}\right)^{T}
$$

The element of the kth layer is a single-level sequencing with the criterion for the jth element on the K-1th layer

$$
\begin{gathered}
u_{j}^{(k)}=\left(u_{1 j}^{(k)}, u_{2 j}^{(k)} \cdots, u_{n_{k} j}^{(k)}\right)^{T} \\
j=1,2 . \cdots, n \cdot k=1,2, \cdots, n_{k}
\end{gathered}
$$

The weight of the element is zero, no jth element constraint, so the $\mathrm{Nk}^{*} \mathrm{~N}$ order matrix can be obtained.

$U^{(k)}=\left(u_{1}^{(k)}, u_{2}^{(k)}, \cdots, u_{n}^{(k)}\right)=\left(\begin{array}{cccc}u_{11}^{(k)} & u_{12}^{(k)} & \cdots & u_{1 n}^{(k)} \\ u_{21}^{(k)} & u_{22}^{(k)} & \cdots & u_{2 n}^{(k)} \\ \vdots & \vdots & \vdots & \vdots \\ u_{n_{k} 1} & u_{n_{k} 2}^{(k)} & \cdots & u_{n_{k} n}^{(k)}\end{array}\right)$

The jth column in $U(\mathrm{k})$ is a single-level sequencing in $\mathrm{kth}$ element of the kth layer, which is the criterion for the jth element on the k-1th layer.

The next mentioned is general ranking of the elements on the kth layer to the total target.

$$
\begin{gathered}
w^{(k)}=\left(w_{1}^{(k)}, \cdots, w_{n}^{(k)}\right)^{T} \\
w^{(k)}=U^{k} w^{k-1}=\left(\begin{array}{cccc}
u_{11}^{(k)} & u_{12}^{(k)} & \cdots & u_{1 n}^{(k)} \\
u_{21}^{(k)} & u_{22}^{(k)} & \cdots & u_{2 n}^{(k)} \\
\vdots & \vdots & \vdots & \vdots \\
u_{n_{k} 1} & u_{n_{k} 2}^{(k)} & \cdots & u_{n_{k} n}^{(k)}
\end{array}\right)\left(\begin{array}{c}
w_{1}^{(k-1)} \\
w_{2}^{(k-1)} \\
\vdots \\
w_{n}^{(k-1)}
\end{array}\right)= \\
\left(\begin{array}{c}
\sum_{j=1}^{n} u_{1 j}^{(k)} w_{j}^{(k-1)} \\
\sum_{j=1}^{n} u_{2 j}^{(k)} w_{j}^{(k-1)} \\
\vdots \\
\sum_{j=1}^{n} u_{n_{k} j}^{(k)} w_{j}^{(k-1)}
\end{array}\right)
\end{gathered}
$$

And

$$
w_{i}^{(k)}=\sum_{j=1}^{n} u_{i j}^{(k)} w_{j}^{(k-1)}, i=1,2, \cdots, n_{k}
$$

Computing the $w_{i}^{(k)}$ weight of all factors at a certain level for the relative importance of the highest level (total target) is noted the total order of the levels. This process is carried out in order from the highest to the lowest level.

\section{Model Application}

High-speed rail drive regional economic growth by increasing investment and stimulating demand. Economic development is the primary goal in a region, and how to measure the standards of regional development, mainly economic growth.

High-speed rail has direct and indirect effects on regional economic development. The former mainly refers that the economic benefits are obvious; the latter's economic benefits appearance requires a period of time, and it needs to be linked to multiple links to reflect economic benefits. Establishing an indicator system needs considers influence factors. The first level is direct and indirect impact. The second-level have 6 indexs, which are respectively regional passenger traffic, regional investment benefits, node accessibility, industrial structure, urbanization levels, and tourism development.

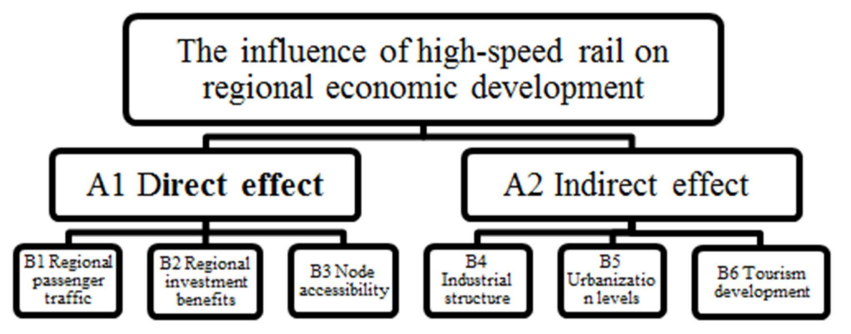

Figure 1. Hierarchical structure model.

According to the experts' direct and indirect effects on the regional economic development of the high-speed rail by the comparison matrix of the first-level indicators is constructed.

Table 4. The importance scale judgment matrix.

\begin{tabular}{lll}
\hline & A1 & A2 \\
\hline A1 & 1 & 5 \\
A2 & $1 / 5$ & 1 \\
\hline
\end{tabular}

As for provided the calculate results, the eigenvectors $\mathrm{w}=(0.8333,0.1667) \mathrm{T}, \lambda \max =2.0000, \mathrm{CR}=0.0000$ by using MATLAB software to calculate, the weight of the direct influence is 0.8333 , and the weight of the indirect influence is 0.1667 . The order of their importance is direct influence, indirect influence.

Table 5. The second level judgment matrix (Direct effect).

\begin{tabular}{lll}
\hline & B1 & B2 \\
\hline B1 & 1 & 5 \\
B2 & $1 / 5$ & 1 \\
B3 & $1 / 2$ & 6 \\
\hline
\end{tabular}

The result demonstrates that the eigenvectors $\mathrm{w}=(0.5498,0.0821,0.3681) \mathrm{T} \lambda \max =3.0858, \mathrm{CR}=0.0825$ by using MATLAB software to calculate. And the order of weight for the indirect influence is regional passenger traffic, node accessibility regional investment benefits.

Table 6. The second level judgment matrix (Indirect effect).

\begin{tabular}{lll}
\hline & B4 & B5 \\
\hline B4 & 1 & $1 / 3$ \\
B5 & 3 & 1 \\
B6 & 3 & $1 / 2$ \\
\hline
\end{tabular}

Based on the computation, the eigenvectors $\mathrm{w}=(0.1396,0.5278,0.3325) \mathrm{T} \lambda \max =3.0536, \mathrm{CR}=0.0667$ by using MATLAB software to calculate. And the order of weight for the indirect influence is urbanization levels, tourism development, industrial structure. 
Table 7. The second level judgment matrix (Indirect effect).

\begin{tabular}{lll}
\hline & B4 & B5 \\
\hline B4 & 1 & $1 / 3$ \\
B5 & 3 & 1 \\
B6 & 3 & $1 / 2$ \\
\hline
\end{tabular}

Table 8. Weighting statistics of each evaluation index.

\begin{tabular}{llll}
\hline & Indexes & Weight & Sums \\
\hline \multirow{3}{*}{ A1 } & B1 & 0.4582 & \\
& B3 & 0.3067 & 0.8333 \\
& B2 & 0.0684 & \\
A2 & B5 & 0.0233 & \\
& B6 & 0.0880 & 0.1667 \\
\hline
\end{tabular}

In the identified indicators, The weight of the direct effect is 0.8333 , and the weight of the indirect effect is 0.1667 for the middle layer elements in AHP. The direct effect is greater than the indirect for high-speed rail on regional economic development.

Among the three direct effect indicators, the weight of regional passenger traffic is 0.4582 , the weight for node accessibility is 0.3067 , and the weight for regional investment benefit is 0.0684 . With the emergence of high-speed rail, it contribute to increasing node accessibility and enhancing the number of regional passenger traffic.

Similarly, the proportion of urbanization levels is 0.0233 , the proportion of urbanization level the weight of tourism development is 0.0880 , and the weight of regional industrial structure is 0.0554 . The development of high-speed rail largely promotes urbanization level and tourism industry.

\section{Discussion}

As mentioned above, the this research explores effect factors affecting the reginal economics of high-speed rail and evaluates We discussour key findings as follows:

1. From the Hierarchical structure model in Figure 1, the first level is direct and indirect impact by previous studies $[10,22]$. However, from the existing literature, we newly added the other influence economics factors to improve the factor system, regional passenger traffic, regional investment benefits, node accessibility, industrial structure, urbanization levels, and tourism development. These factors can significantly measure the high speed rail [7, 19, 21].

2. It was found that there was significant relatives in industry structure in Table 8 . HSR does not reduce the service industry agglomeration of the core and small-sized cities that are also situated along the rail lines [25]. Additionally, the impacts on economics of high speed rail have other aspects. To our knowledge, it is because the construction of high speed rail has been in a rapid development period since 2005, it has great effect on the regional passenger traffic, node accessibility, and tourism development.

\section{Conclusion}

HSR has received an increasing attention worldwide in recent years given that node accessibility has been greatly improved both in terms of time savings and passenger volume. However, the debate on the merit of HSR investment has reached a consensus given the concerns of its high construction cost and economic benefits. This study is conducted to address economies effects on the massive high-speed rail in China: what the impact of HSR is on regional economic effects. The issue investigated in 2 dimensions. First, a theoretical framework for accessing the influence of HSR on reginal economics was developed. Combined some domestic literature, it identified 6 indicators, respectively regional passenger traffic, regional investment benefits, node accessibility, industrial structure, urbanization levels, and tourism development. Second, the direct and indirect effects of high-speed railways on regional economic development were quantitatively analyzed by analytic hierarchy process. Finally, there are some conclusions that the direct impact is more significant in the high-speed rail on economic development than indirect. And the construction of transportation infrastructure can improve local location conditions. The high-speed rail and the regional economy are mutually reinforcing and dependent. It not only increases the regional passenger traffic, but also the accessibility of the nodes. It also has a little effect on the development of regional urbanization and tourism, which can improve employment and cultural industries. In summary, based on the analytic hierarchy process, the impact of high-speed rail on regional economic development can provide a reference for local regional economy development. For example, if the government wants to improve the development of regional tourism, it may consider building a high-speed rail station. But there are still some limitations in our works: (1) lacking of empirical study; (2) existing uncertain factors of HSR.

\section{Acknowledgements}

I would like to thank my supervisor Dr. Jian Ma and Wei Wang for helping me explore my potential in conducting research and developing the idea for my thesis.

\section{Appendix}

Questionnaire survey on economicindicators effect of high-speed railway

Dear expert:

Hello! Thank you for taking time to participate this survey. The main purpose of this survey is to construct a scientific and reasonable evaluation index system and to adjust and modify economic impact weights of high-speed rail by evaluation index system through your answer providing a basis for studying quantitatively the high-speed railway on regional economy. The data of this survey is only used for scientific research. Please fill in the truth. 
Table A1. The importance scale judgment matrix.

\begin{tabular}{ll}
\hline Importance scale & Meanings \\
\hline 1 & Unimportant \\
3 & Not so important \\
5 & Generally important \\
7 & Important \\
9 & Very important \\
$2,4,6,8$ & Intermediate value \\
\hline
\end{tabular}

Table A2. Comparing the first layer index.

\begin{tabular}{lll}
\hline Target layer & The importance scale & Indicators \\
\hline $\begin{array}{l}\text { The influence of high-speed rail } \\
\text { on regional economic }\end{array}$ & Direct effect \\
$\begin{array}{l}\text { development } \\
\begin{array}{l}\text { The influence of high-speed rail } \\
\text { on regional economic } \\
\text { development }\end{array}\end{array}$ & $\begin{array}{l}\text { Indirect } \\
\text { effect }\end{array}$ \\
\hline
\end{tabular}

Table A3. Comparing the second layer index (Direct effect).

\begin{tabular}{lll}
\hline Target layer & The importance scale & Indicators \\
\hline Direct effect & Regional passenger traffic \\
Direct effect & Regional investment benefits \\
Direct effect & Node accessibility \\
\hline
\end{tabular}

Table A4. Comparing the second layer index (Indirect effect).

\begin{tabular}{lll}
\hline Target layer & The importance scale & Indicators \\
\hline Indirect effect & Industrial structure \\
Indirect effect & Urbanization levels \\
Indirect effect & Tourism development \\
\hline
\end{tabular}

\section{References}

[1] Jin Niu. Based on the Analytic Hierarchy Process and Fuzzy Comprehensive Evaluation of core competence of China's High-Speed Rail evaluation (In chinese) [D]. Lanzhou University of Technology, 2017.

[2] Haibin Jiang, Jiangang XU, YI QI. The Influence of Beijing-Shanghai High-speed Railways on Land Accessibility of Regional Center Cities (in Chinese) [D]. Acta Geographica Sinica 2010, 65 (10).

[3] He Lan. The Impact of Harbin-Dalian High-speed Railways on Accessibility and Economic Ties in the Major Cities Along (In Chinese) [D]. Ji Lin university in China, 2017.

[4] Blum U, Havnes K E, Kar 1sson C. Introduction to Special Issue, The Regional and Urban Effects of High-speed Trains [J]. The Annals of regional Science, 1997, 319 (1): 1-20.

[5] Coto-Millan Pablo, Vicente Inglada. Belen Rey. Effects of Network Economics in High-speed Rail: the Spanish case [J]. Annals of Regional Science 2007 (41): 911-925.

[6] Zhu, Y (Zhu, Yi) 1, 2; Diao, M (Diao, Mi) 3;Fu, G (Fu, Gang) 4. The evolution of accessibility surface of China in the high-speed-rail era [J]. Environment and Planning A. 2016, Vol. 48 (No. 11): 2108-2111.

[7] Xu, W;Zhou, J;Yang, L;Li, L. The implications of high-speed rail for Chinese cities: Connectivity and accessibility [J]. Transportation Research Part A: Policy \& Practice. 2018: 308-326.

[8] Ruqing Yao. Researching the Influence toward Hangzhou of High Speed Railway of Shanghai to Hangzhou [J]. Modern
Urban Research, 2010 (6).

[9] Jintao Ren. A Study of How High-Speed Railway Affects County Industry Development [J]. Open Journal of Social Sciences. 2018, Vol. 6 (No. 5): 69-80.

[10] Huiyan YU. Research on Impact of Harbin-Dalian High-speed Railway on Liaoning Economic Development (In Chinese) [D]. Dalian Jiaotong University, 2015.

[11] Fernand Martin. Justifying a high-speed rail project: social value vs. regional growth [J]. Regional Growth, 2000, 31 (3): 8-9.

[12] Huarong Gao. Research on the Impact of High-speed Railway on Regional Economic Development-A case Study of Jinan-Qingdao DPL (In Chinese) [D]. Beijing Jiaotong University, 2017.

[13] Zhengze Yang. Research on National Economic Atributions and Investment Performance of High Speed Railway (In Chinese) [D]. BeiJing University, 2015.

[14] Xiulan Jiang. Discussion on the Influence of High Speed Railway on the Economic Development of Beijing-Tianjin-Hebei Metropolitan Area (In Chinese) [J]. China Railway, 2009 (8): 14-16.

[15] Gerard Mathieu. French TGV High-speed Train System and its Economics Evaluation [J]. Shang Hai High-speed Transportation international. 1993, 11: 44-13.

[16] Chen, Zhenhua. Measuring the regional economic impacts of high-speed rail using a dynamic SCGE model: the case of China. [J]. European Planning Studies. 2019, Vol. 27 (No. 3): 483-512.

[17] Chen, Zhenhua;Haynes, Kingsley E. Impact of high-speed rail on regional economic disparity in China [J]. Journal of Transport Geography. 2017: 80-91.

[18] Yao, Shujie;Zhang, Fan;Wang, Feng;Ou, Jinghua. Regional economic growth and the role of high-speed rail in China. [J]. Applied Economics. 2019, Vol. 51 (No. 32): 3465-3479.

[19] Zhang Li. Research on the Benefit of High-speed Rail's Investment Promotion [J]. Information Technology Journal. 2014, Vol. 13 (No. 7): 1371-1375.

[20] Xin Wang;Songshan Huang;Tongqian Zou;Hui Yan. Effects of the high speed rail network on China's regional tourism development [J]. Tourism Management Perspectives. 2012: 34-38.

[21] Cherylynn Becker;Babu P. George. Rapid Rail Transit and Tourism Development in the United States [J]. Tourism Geographies. 2011, Vol. 13 (No. 3): 381-397.

[22] Li, Leona S. Z.;Yang, Fiona X.;Cui, Chuantao. High-speed rail and tourism in China: An urban agglomeration perspective. [J]. International Journal of Tourism Research. 2019, Vol. 21 (No. 1): $45-60$.

[23] Ömer Faruk Görçün. Impacts of high speed trains on tourism development: A case study of Ankara-Konya high speed rail lines [J]. Journal of Tourism Theory and Research. 2018: 21-28.

[24] Jianping Wang. Research on Impact of High-Speed Railway on Jiangxi Social and and economic development A case Study of Shanghai-Kunming High-speed Railway (In Chinese) [D]. Nanchang University, 2017.

[25] Shao, S (Shao, Shuai) 1;Tian, ZH (Tian, Zhihua) 1; Yang, LL (Yang, Lili) 2. High speed rail and urban service industry agglomeration: Evidence from China's Yangtze River Delta region [J]. Journal of Transport Geography. 2017: 174-183. 